\title{
EFFECTS OF RELAXATION ON ANXIETY AND SALIVARY IgA LEVELS IN PUERPERAE
}

\author{
Cândida Caniçali Primo ${ }^{1}$ \\ Maria Helena Costa Amorim²
}

Primo CC, Amorim MHC. Effects of relaxation on anxiety and salivary IgA levels in puerperae. Rev Latino-am Enfermagem 2008 janeiro-fevereiro; 16(1):36-41.

This experimental study aimed to evaluate the effect of relaxation techniques on anxiety levels, and the relation between anxiety and the concentration of Immunoglobulin A. The study was carried out in a maternity hospital in a city of the State of Espirito Santo, Brazil. The sample was composed of 60 puerperae. The information on the variables: age, education, marital status, type of childbirth, and parity were collected with a specific form; the trait and state of anxiety were based on the State Trait Anxiety Inventory (STAI/IDATE); and the level of salivary IgA was obtained through immunoturbidimetry. The application of the Mann-Whitney, Wilcoxon, and Pearson's correlation statistical tests showed a significant reduction in the levels of the state of anxiety in the experimental group ( $p=0.01)$; there was no correlation between the trait and state variables of anxiety and the salivary IgA level; both groups (experimental and control) showed trait and state of medium-intensity anxiety.

DESCRIPTORS: postpartum depression; anxiety; relaxation techniques; immunoglobulin $A$; psychoneuroimmunology; pregnancy; postpartum period

\section{LOS EFECTOS DEL RELAJAMIENTO SOBRE EL ESTADO DE ANSIEDAD Y EN LOS NIVELES DE IgA EN LA SALIVA DE MUJERES EN PUERPERIO}

Este estudio experimental tiene como objetivos evaluar los efectos de la técnica de relajamiento en los niveles de ansiedad y la relación que existe entre la ansiedad y la concentración de Inmunoglobulina A. El estudio fue realizado en una maternidad, en un municipio del Estado de Espíritu Santo, en Brasil. La muestra estaba constituida por 60 puérperas. Las informaciones referentes a las variables: edad, grado de instrucción, estado civil, tipo de parto y número de hijos, fueron recolectadas por medio de un formulario específico; el trazo y el estado de ansiedad tuvieron como base el Inventario de Ansiedad Trazo y Estado (IDATE), y el nivel de IgA de la saliva a través de la inmunoturbidimetría. La aplicación de las pruebas estadísticas Mann-Whytney, Wilcoxon y la correlación de Pearson mostraron: una disminución significativa de los niveles del estado de ansiedad en el grupo experimental $(p=0,01)$ y la ausencia de correlación entre las variables trazo y estado de ansiedad y el nivel de IgA salivar; los dos grupos (control y experimental) presentaron un valor promedio para Trazo y Estado de ansiedad.

DESCRIPTORES: depresión posparto; ansiedad; técnicas de relajación; inmunoglobulina $A$ psichoneuroinmunología; embarazo; periodo de posparto

\section{EFEITOS DO RELAXAMENTO NA ANSIEDADE E NOS NÍVEIS DE IgA SALIVAR DE PUÉRPERAS}

Este estudo experimental teve como objetivos avaliar os efeitos da técnica de relaxamento nos níveis de ansiedade e a relação entre ansiedade e concentração de imunoglobulina A. Foi realizado em uma maternidade de um município do Estado do Espírito Santo, Brasil. A amostra foi composta por 60 puérperas. As informações referentes às variáveis idade, grau de instrução, estado civil, tipo de parto, paridade foram coletadas por meio de formulário específico; o traço e estado de ansiedade com base no Inventário de Ansiedade Traço e Estado (IDATE) e o nível de IgA saliva através da imunoturbidimetria. A aplicação dos testes estatísticos Mann-Whytney, Wilcoxon e a correlação de Pearson evidenciaram diminuição significativa dos níveis do estado de ansiedade no grupo experimental $(p=0,01)$, ausência de correlação entre as variáveis traço e estado de ansiedade e nível de IgA salivar. Os dois grupos (controle e experimental) apresentaram Traço e Estado de média ansiedade.

DESCRITORES: depressão pós-parto; ansiedade; técnicas de relaxamento; imunoglobulina A; psiconeuroimunologia; gravidez; período pós-parto

\footnotetext{
${ }^{1}$ RN, M.Sc. in Collective Health, Faculty; ${ }^{2}$ RN, Ph.D. in Nursing, Faculty, e-mail: mhcamorim@aol.com. Federal University of Espírito Santo, Brazil
} 


\section{INTRODUCTION}

Maternity is an important event in a woman's life, whose body is physiologically prepared for that. However, it is observed that this event seems to make the woman prone to emotional disorders. This may be evident, since several researchers have described a higher incidence of psychiatric disorders in the postpartum period, ranging from dysphoria and anxiety disorders to depression and puerperal psychosis ${ }^{(1)}$.

The etiology of anxiety and mood swing episodes in women in the postpartum period remains unclear. This period shows significant neuroendocrinal and psychosocial changes, and the interaction of these factors is probably responsible for the pathogenesis of the affective disorders ${ }^{(2)}$.

Anxiety is an emotional state with psychological and physiological components, being a part of human experiences, and it is responsible for the adaptation of the organism to situations of danger. The feeling of anxiety is a common experience and may concern any human being. It affects one out of nine people, approximately ${ }^{(1)}$.

Pregnancy and childbirth are very significant events in a woman's life, and few studies address the effects of anxiety for women and babies in these periods. Studies show that nearly $30 \%$ of women have experienced some kind of anxiety disorder during their lives, and that episodes of anxiety became very frequent during pregnancy and after childbirth ${ }^{(3-4)}$. Furthermore, most cases of postpartum anxiety were preceded by a history of antenatal anxiety ${ }^{(5)}$.

Studies have shown that anxiety may interfere in the concentration of IgA by the sympathetic and parasympathetic nervous systems. The parasympathetic nervous system causes glandular vasodilatation, triggering a very abundant and diluted production of salivary secretion. However, the sympathetic nervous system causes marked vasoconstriction, responsible for the occurrence of a low salivary volume and, consequently, the dry mouth feeling ${ }^{(6)}$

Nowadays, there is an ever-growing application of techniques that include relaxation, when trying to mitigate the stressful factors of modern life. There have been positive results with the use of relaxation techniques in patients, such as stress reduction. In addition, there were reductions in anxiety, hostility, blood pressure, pain, nervousness, and depression $^{(7)}$.
The use of music as a relaxation therapy has been used in several areas. Research with students exposed to stressing factors during an oral presentation verified that, when there was music, students' anxiety decreased, and the music increased the levels of salivary $\operatorname{Ig} \mathrm{A}^{(8)}$. Reiki is another practical intervention that has been used with the goal of bringing balance and harmony for the body, mind, and soul. It has shown to decrease anxiety, and improve relaxation and immunological functioning, such as increasing IgA levels ${ }^{(9)}$.

Psychoneuroimmunology has studied the connections between tension-related changes on immune responses, and consequently in the susceptibility to diseases and the possibility of recovering from illness. Individuals with serious psychoneuroimmunologic disorders caused by undergoing stressful situations demonstrate that the immune and nervous systems are both involved in the physical and psychic processes of adaptation to the day-to-day stress ${ }^{(10)}$.

Taking into consideration the evidence that the puerperal period may cause anxiety, studies in our socio-cultural context should be implemented. Such studies should aim to understand the factors affecting this phenomenon, so that nurses and other health professionals involved in puerperal care may intervene. This study aims to contribute to improve the quality of nursing health care to puerperae, and become a reference for anxiety assessment in the puerperal period. The objectives are to evaluate the effect of relaxation techniques on anxiety levels, and to examine the relation between anxiety and salivary IgA in the puerperae.

\section{METHODOLOGY}

This is an experimental study, performed in a maternity hospital in the municipality of Serra, state of Espírito Santo, Brazil. Sixty puerperae, hospitalized in non-private rooms in the maternity, were selected for the study. Thirty were assigned to the control group and 30 to the experimental group. The size of the sample was calculated for both groups considering a $5 \%$ level of significance, testing power of $80 \%$, minimum difference to be detected of $4 \mathrm{mg} / \mathrm{dl}$, and standard deviation of 5.5 . Therefore, the resulting sample size was 30 individuals for each group. 
The sample was comprised of puerperae who had given birth in this institution. In addition, the women's pregnancy lasted at least 37 weeks, they were hospitalized in non-private rooms with their newborn child, and had not had any infectious problems during pregnancy or during the period of study. Moreover, they should not have a personal or family history of psychiatric disease or use any illicit drug. All of the puerperae received information about the study, and signed a consent form agreeing to participate.

The following variables were used: age, level of education, marital status, type of childbirth, parity, trait and state of anxiety, and salivary IgA level.

After several anxiety scales had been analyzed, we chose to use the STAI instrument - State Trait Anxiety Inventory. This inventory is named IDATE in Brazil, and has proven be very useful and precise for the identification of anxiety in the puerperal period, despite it not being specific for this moment ${ }^{(11)}$.

STAI is comprised of two parts, with 20 statements each. The anxiety trait evaluates how the woman normally feels in her life, or, in the present case, how she felt before childbirth, using the scale: almost all the time $=4$, frequently $=3$, sometimes $=$ 2 , almost never $=1$. The anxiety state evaluates the woman's state of anxiety at the moment of the postpartum interview, measured in the scale: no $=1$, a little $=2$, a lot $=3$, totally $=4$. Scoring for each instrument varies from 20 to 80 , and the result is classified according to the score ${ }^{(10)}$.

The anxiety trait was evaluated in both control and experimental groups, in the first 24 hours after childbirth. The anxiety state was evaluated in the first 24 hours after childbirth and one week after.

The puerperae from the experimental and control group had their salivary IgA concentration measured. Two samples were collected from each mother by the researcher, one up to 24 hours after childbirth and another seven days after, in both groups. The samples of saliva were collected between 3 and 5 PM, always before dinnertime, and before performing the relaxation techniques with the experimental group. The total IgA concentration was determined by immunoturbidimetry.

The experimental group received instructions according to the relaxation technique proposed by Benson ${ }^{(8)}$, which uses four essential elements: a quiet environment, a mental device, a passive attitude and a comfortable position. The relaxation technique was individually explained to each puerpera during the period they were in the hospital (two days), so that they could learn and perform them twice a day; once after waking up and another before sleeping.

According to the Ministry of Health, puerperae who are clinically well may be released from care after 48 hours of normal childbirth and 72 hours after cesarean childbirth ${ }^{(12)}$. Therefore, we chose to instruct patients for two consecutive days, because of their short stay in the maternity and difficulty to return to the institution during the puerperal period, due to the need to protect the newborn and the patient's need to recover.

Collection of information, registry of instruments, and the performance of the IgA tests were started after the approval of the Research Ethics Committee of the Biomedical Center of the Federal University of Espírito Santo, starting in April/2004 and ending in March/2005.

The analysis of the data was performed with the Social Package for Statistical Science (SPSS) 11 (2002), and the level of significance was fixed at 5\%, corresponding to á $=0.05$ (level of reliability of 95\%). The Mann-Whitney test was used to compare the levels of anxiety between the control and the experimental groups. The Wilcoxon test was applied to verify the level of anxiety in each group at each moment. Pearson's correlation was used to evaluate the correlation between the anxiety trait and anxiety state variables.

\section{RESULTS}

No significant differences were found between the control and the experimental groups regarding the variables age, level of education, marital status, type of childbirth, and parity.

In both control and experimental groups, the prevalent age range was from 19 to 25 years (60\% and $56.7 \%$, respectively). As for the level of education, $63.3 \%$ of the experimental group and $36.6 \%$ of the control group had not concluded elementary education; $30 \%$ of the women had either a complete elementary education level or an incomplete high school level. Such predominance of women with elementary education levels may occur because the maternity hospital is a public institution, catering mainly to a low-income and low-education clientele. 
Regarding marital status, most women in both groups live with their partner in a stable relationship (73.3\% in the control group and $66.7 \%$ in the experimental group). There was a higher incidence of normal childbirth among the puerperae, with over $90 \%$ in both groups, maybe because the hospital maternity attends low-risk cases. As for parity, there was a prevalence of multiparity women, with two or more children $(66.7 \%$ in the control group and $70 \%$ in the experimental group).

A study describing the epidemiological profile of 1,335 puerperae cared for in this maternity hospital from January to December/2002 found similar results for the variables age, marital status, level of education, and type of delivery ${ }^{(13)}$.

The anxiety evaluated in this study refers to "natural anxiety" as an everyday phenomenon, with a motivating function that mobilizes resources for the adaptation of the individual to new situations. When anxiety cases are simpler, superposition of symptoms is higher, as well as the lack of specificity in the clinical condition. In this sense, anxiety and depression may be part of the general "stress process"(1).

According to Figure 1 , puerperae in both groups showed an average anxiety trait; Thus, there was no significant difference between the groups ( $p$ $=0.137)$. The same anxiety trait behavior was observed in other studies ${ }^{(5,11)}$.

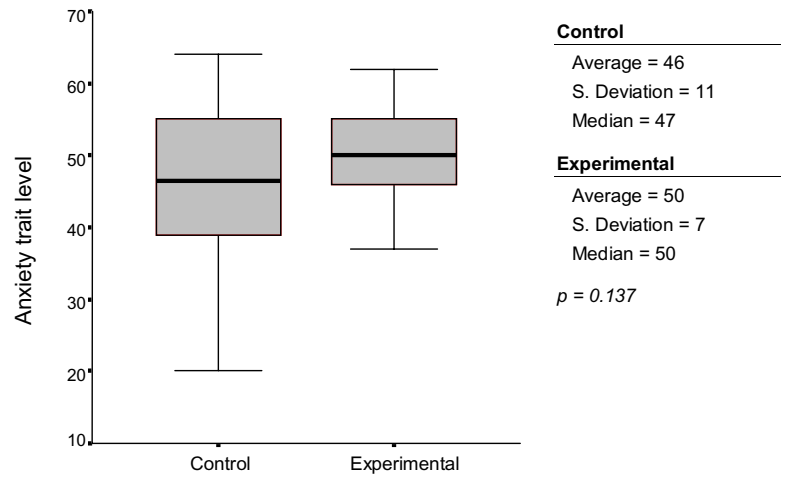

Figure 1 - Anxiety trait level in the puerperae studied in the control and experimental groups. Serra, ES, April/2004 to March/2005

Figure 2 compares the control group with the experimental group, regarding anxiety levels, showing that in both groups medium-intensity anxiety prevailed in the first moment (24 hours after childbirth), without a significant difference between both groups ( $p=$ 0.122 ). Figure 2 also shows that the control group puerperae showed higher anxiety state values than the women in the experimental group one week after childbirth. However, no significant statistical difference was found between both groups ( $p=0.236)$.

Another study performed with 120 women who had a normal or cesarean delivery in hospitals in the region of Vitória in Espírito Santo, using the STAI instrument, also found a medium-intensity level of postpartum anxiety ${ }^{(11)}$.

A study with women in England found that $13 \%$ showed anxiety in the third trimester of gestation, while only $8.1 \%$ reported anxiety after 8 weeks of childbirth. Of the women who showed high levels of anxiety after childbirth, $64 \%$ have also reported the presence of anxiety during pregnancy, concluding that most cases of postpartum anxiety were preceded by a history of anxiety in the antenatal period ${ }^{(3)}$.

Another study, performed in Sweden with 1,465 women, found that only $5.9 \%$ showed some anxiety disorder during gestation ${ }^{(4)}$. A study analyzing the anxiety of 634 French pregnant women through SAIT has found an average state of anxiety during the $20^{\text {th }}$ and $28^{\text {th }}$ week of gestation ${ }^{(5)}$.

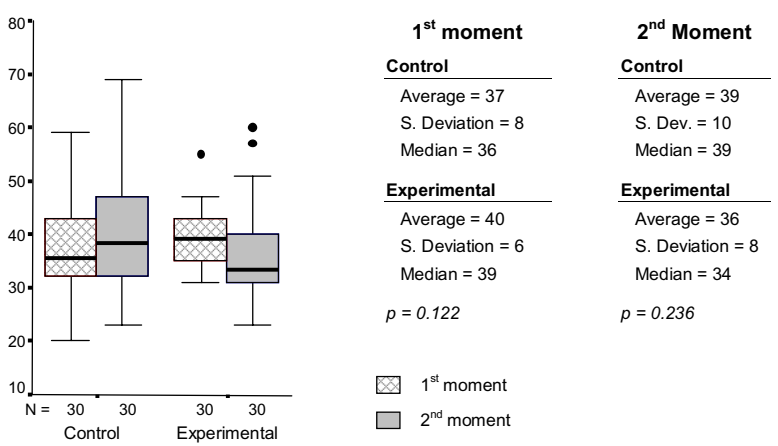

Figure 2 - Comparison of the puerperae's anxiety state levels in both control and experimental groups during childbirth and one week after childbirth. Serra, ES, April/2004 to March/2005

Figure 3 shows that, when the average anxiety level within each group is evaluated separately, one week after childbirth, the control group maintained a state of average anxiety, while the experimental group showed a decrease in their scores. Thus, when the anxiety states of the control group in the first and second moments are compared, no significant differences were observed ( $p$ $=0.465)$. However, in the experimental group, $a$ considerable difference was verified $(p<0.01)$, showing that there was a noteworthy decrease in the anxiety state levels in the puerperae submitted to relaxation. 


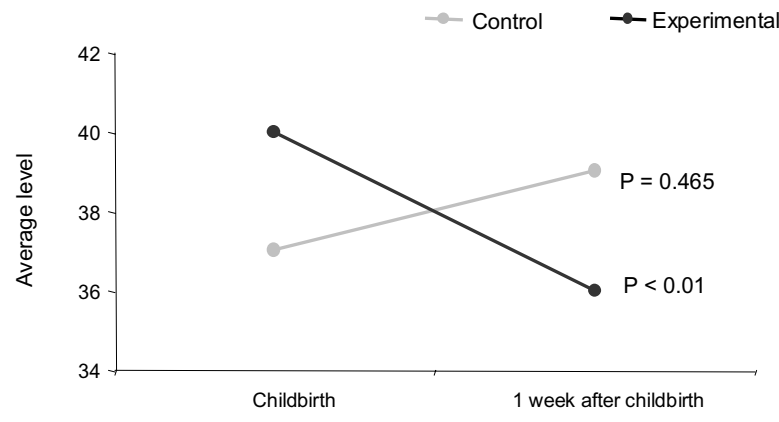

Figure 3 - Difference of the average levels in the anxiety state of the puerperae in the control and experimental groups during and after childbirth. Serra, ES, April/2004 to March/2005

Relaxation techniques are considered simple and effective, and nurses may use them to reduce the inpatients' anxiety. Besides, when caring for the client's body, nurses have the chance to perform a routine of corporeal awareness that may help patients to understand and perceive their body functions better, which helps to eliminate the effects caused by tension ${ }^{(10)}$.

Several authors demonstrate herein that nursing interventions or other types of relaxation can change anxiety levels, but studies focusing on women in the puerperal period were not found.

A study with women in labor has shown that massage is an effective nursing intervention capable of mitigating pain and anxiety during childbirth, and that the participation of the partner in the massage may have a positive influence over the childbirth experience ${ }^{(14)}$.

Research evaluating the effect of breathing and relaxation techniques on pain and anxiety during parturition concluded that the techniques applied did not reduce the intensity of the pain, but promoted longer maintenance of low anxiety levels ${ }^{(14)}$.

It is observed that there is no significant correlation between the anxiety states of the studied sample, evaluated at the second moment, with the levels of salivary IgA at the moment of the second collection. (Control group: $r=0.213 ; p=0.259$; Experimental group: $r=-0.277 ; p=0.139$ ).
The effects of maternal mood swings, such as depression and anxiety, during pregnancy on the emotional and psychological development of the child remain unclear. However, there is evidence of a causal relation between maternal psychological alterations during gestation and after childbirth and neonatal complications ${ }^{(4)}$.

The presence of anxiety during pregnancy is associated with adverse perinatal results, particularly preterm births and low birth weight, and there is also a risk for developing emotional problems in children ${ }^{(5,16)}$.

As such, knowing the feelings and desires of a pregnant woman may help to organize a better mental health care for women in the antenatal and puerperal periods, allowing for the elaboration of proposals to reduce the risks of obstetric and neonatal complications.

\section{CONCLUSION}

There was a significant reduction in the anxiety state levels in the experimental group $(P=0.01)$; There was no correlation between the anxiety trait and state variables and the salivary IgA level of the puerperae. Therefore, with the results obtained, we understand that the practice of relaxation techniques contributes significantly to improve the emotional state of the women, reducing anxiety in the puerperal period.

The puerperal period is one of physical and emotional changes, experienced differently by each woman. These transformations may cause fear, doubt, and distress regarding the ability of caring for a new being, the newborn, and still having to deal with all the activities that were performed before pregnancy.

The nurse should commit to listening to the puerpera's needs, conveying the necessary support and trust so that the woman can become stronger and able to lead her life with more autonomy.

Therefore, we notice that nursing interventions such as relaxation need to be included in nurses' day-to-day caring activities, since this would bring them closer to the client, improve the quality of nursing health care and promote the effective recognition of this profession.

\section{REFERENCES}

1. Kaplan HI, Sadock BJ, Grebb JA. Compêndio de psiquiatria: ciência do comportamento e psiquiatria clinica. Porto Alegre: Artmed; 2003.

2. Brockington I. Postpartum psychiatric disorders. Lancet 2004 January; 363(9405):303-10.
3. Heron J, O'Connor TG, Evans J, Golding J, Glover V. The ALSPAC Study Team. The course of anxiety and depression through pregnancy and the postpartum in a community sample. J Affect Disord 2004 May; 80(1):65-73.

4. Andersson L, Sundström-Poromaa I, Wulff M, Aström $M$, Bixo M. Neonatal outcome following maternal antenatal depression and anxiety: a population based study. Am J Epidemiol 2004 May; 159(9):872-81. 
5. Dayan J, Creveuil C, Herlicoviez M, Herbel C, Baranger E, Savoye $C$, et al. Role of anxiety and depression in the onset of spontaneous preterm labor. Am J Epidemiol 2002 February; 155(4):293-301.

6. Clow A, Lambert S, Evans P, Hucklebridge F, Higuchi K. An investigation into asymmetrical cortical regulation of salivary S-IgA in conscious man using transcranial magnetic stimulation. Int J Psychophysiol 2003 January; 47(1):57-64.

7. Benson H. The relaxation response. In: Goleman D, Gurin J. Mind/body medicine: how to use your mind for better health. Boston: Consumers Reports Books; 1993, p. 233-57.

8. Knight WE, Rickard NS. Relaxing music prevents stressinduced increases in subjective anxiety, systolic blood pressure, and heart rate in healthy males and females. J Music Ther 2001 Winter; 38(4):254-72.

9. Wardell DW, Engebretson J. Biological correlates of reiki touch healing. J Adv Nurs 2001; 33(4):439-45.

10. Amorim MHC. A enfermagem e a psiconeuroimunologia no câncer de mama. [doutorado]. Rio de Janeiro (RJ): Escola de Enfermagem Ana Nery/UFRJ; 1999.

11. Amorim MHC, Repossi CD, Leite LD. Avaliação do nível de ansiedade e imunoglobulina $A$ em mulheres de parto normal e cesárea. In: $11^{\circ}$ Congresso Panamericano de Profesionales de Enfermería e $55^{\circ}$ Congresso Brasileiro de Enfermagem, 2003, Novembro 3-7; Rio de Janeiro, Rio de Janeiro. Rio de Janeiro: ABEn; 2003.

12. Ministério da Saúde (BR) Secretaria de Políticas de Saúde. Área Técnica de Saúde da Mulher. Parto, aborto e puerpério: assistência humanizada à mulher. Brasília (DF): Ministério da Saúde; 2001.

13. Primo CC, Amorim MHC, Castro DS. Perfil Social e Obstétrico das Puérperas de uma Maternidade. Rev Enferm UERJ 2007 abril-junho; 15(2):161-7.

14. Chang M, Wang S, Chen C. Effects of massage on pain and anxiety during labour: a randomized controlled trial in Taiwan. J Adv Nurs 2002; 38(1):68-73.

15. Almeida NAM, Sousa JT, Bachion MM, Silveira NA. Utilização de técnicas de respiração e relaxamento para alívio de dor e ansiedade no processo de parturição. Rev Latino-am Enfermagem 2005 janeiro-fevereiro; 13(1):52-8.

16. O'Connor TG, Heron J, Glover V, Alspac Study Team. Antenatal anxiety predicts child behavioral/emotional problems independently of postnatal depression. J Am Acad Child Adolesc Psychiatry 2002 December; 41(12):1470-7. 